\title{
Correlation of Human and Horse Heart Rates during Equine-Assisted Therapy Sessions with At-Risk Youths: A Pilot Study
}

\author{
Macy Drinkhouse, ${ }^{\mathrm{a}, \mathrm{b}}$ Sheri SW Birmingham, ${ }^{\mathrm{a}}$ Robyn Fillman, ${ }^{\mathrm{a}}$ and Holly Jedlicka ${ }^{\mathrm{a}}$
}

\begin{abstract}
Minimal research has been done to examine the cause of the positive results of animal-assisted therapy. This study examines the correlation between horse and human heart rate, an involuntary stress response, which may allow the mechanisms of potential therapeutic benefits to be further understood. Horse and human heart rates were recorded during equine-assisted therapy sessions, compared, and the significance of human and horse heart rate correlation was documented. Results indicate that each incidence of correlating changes in the heart rates appeared to be the result of external stimuli. Findings are discussed and recommendations for future trials with controlled environments are proposed.
\end{abstract}

Keywords: heart rate, animal-assisted therapy, equine-assisted therapy, horse, at-risk youth

\section{Introduction}

Animal-assisted therapy was first documented as a legitimate therapeutic technique in 1969, by Levinson in PetOriented Child Psychotherapy. Since then, animal-assisted therapy has been a major topic of interest, with many anecdotal reports on its beneficial therapeutic effect (Klontz, Bivens, Leinart \& Klontz, 2007; Marr et al., 2000; Mason \& Hagan, 1997). In recent years, equine-assisted therapy has become a widespread method as an adjunct to traditional therapeutic techniques. This study does not examine the influence of therapy, but rather seeks empirical evidence that there is involuntary, mutual animal/human influence during therapy sessions. Only through physiologic, blinded measures of involuntary responses can the anecdotal reports of enhanced influence of the use of equine therapy during cognitive/behavioral therapy be empirically proven to have any effect. Heart rate is a well-cited physiologic manifestation of both the human and animal sympathetic nervous system in response to physical, mental and environmental stressors. Autonomic regulation of the cardiovascular system may be evidence that physiologic co-influence is occurring during animal-assisted therapy sessions. Over the years, there have been many studies that have documented marked effects that social interactions have on the cardiovascular activity of animals (de Jong et al., 2000; Lynch, Fregin, Mackie \& Monroe, 1974; Lynch and Gantt, 1968; Rietmann et al., 2004). According to a study by von Borell et al. (2007) heart rate variability has also been applied increasingly in veterinary and behavioral research to investigate changes in sympathovagal balance related to conditions ranging from stress (Rietmann et al., 2004) to emotional states (Palestrini, Previde, Spiezio \& Verga, 2005; Visser et al., 2002) in a number of farm and companion animal species. Based upon these previous studies, the authors chose heart rate as the involuntary parameter to use as a measure of horse/human coinfluence in this study. We hypothesize that through the synchronization of animal and human involuntary responses, the client is affected. This study was designed to examine the correlation between horse and human heart rates, which may allow the mechanisms of potential therapeutic benefits to be further understood.

\section{Materials and Methods}

Each session followed the Equine Assisted Growth and Learning Association (EAGALA) model of therapy. The EAGALA model of therapy is a specific method of utilizing equines as part of a therapy or learning session. At least one member of the treatment team must be certified through EAGALA in order to provide this type of therapy.

Twelve equine-assisted therapy sessions were conducted at a local equine therapy center, a facility that specializes in the treatment of at-risk youth. These youth were identified as those struggling to maintain themselves at home, at school or in the community. They may have had mental health diagnosis or be struggling behaviorally. The director of the center, a licensed social worker, conducted all sessions. A certified equine specialist and a videographer, who rotated between two researchers, were also present during each session. Sessions consisted of typical EAGALA equineassisted therapy session techniques, which consist of unmounted activities that provide a solution-focused, experiential form of therapy. The sessions frequently involved game playing in order to allow the client to participate in experiential therapy. This is a therapeutic approach that encourages clients to identify and address issues through activities rather than through talk. The clients were at-risk youth who were not previously clients of the center and who volunteered to participate in four sessions each for the purpose of the study. Sessions were conducted weekly and the three horses that worked as part of the study were selected based upon personality, selected activity, and need of the client. The horses ranged greatly both in size, age and breed. The sessions were conducted in an indoor arena setting with minimal outside windows and doors to minimize external variables. 
Heart rates were recorded in beats per minute in 5second intervals, by Polar Trainer Plus (RS800) and Polar Trainer Equine (RS800CX) horse heart rate monitors, worn by the human and horse respectively. Both wore an electrode strap around their upper thorax. Data were collected in watches fastened near the electrode on the horse and on the wrist of the person. Heart rate recordings were started simultaneously at the beginning of each therapy session. Each session was videotaped and started within a time period of five minutes of the heart rate monitors due to logistical constraints.

The heart rate data were statistically analyzed using the Pearson product-moment correlation co-efficient (PPMC) in order to determine if a correlation existed between horse and client heart rates throughout the therapy session. The statistically significant sessions were then further analyzed in order to determine if a certain portion of the data were more significant. Each significant session was broken into time segments based upon graphical trends. The number of time segments that a session was broken down into ranged from five to eight. Each time segment was then analyzed for statistical significance. The significant time segments were then matched with video data to examine possible bias for correlation, such as changes in physical activity. The video data were evaluated for significant environmental events by a blind observer with no knowledge of the heart rate devices affixed to the subjects.

\section{Results}

Out of the ten sessions successfully recorded, sessions G, $\mathrm{H}$, and I proved to be statistically significant with a Pearson Correlation Coefficient above 0.800 (Table 1). Plots of the client and horse average heart rate during these three sessions are given in Figures 1, 2, and 3. No client/horse combination was duplicated within these three sessions.

Table 1: Pearson Analysis of Correlation between Client and Horse Heart Rates

\begin{tabular}{|llcccl|}
\hline Session & \multicolumn{1}{c}{ Date } & $\begin{array}{l}\text { Client } \\
\text { Number }\end{array}$ & $\begin{array}{l}\text { Horse } \\
\text { Number }\end{array}$ & $\begin{array}{l}\text { Pearson } \\
\text { Correlation }\end{array}$ & $\begin{array}{l}\text { p- } \\
\text { value }\end{array}$ \\
\hline $\mathrm{A}$ & $4 / 7 / 09(1)$ & 1 & 1 & 0.256 & 0.000 \\
\hline $\mathrm{B}$ & $4 / 7 / 09(2)$ & 2 & 2 & 0.083 & 0.022 \\
\hline $\mathrm{C}$ & $4 / 21 / 09(1)$ & 2 & 1 & 0.185 & 0.000 \\
\hline $\mathrm{D}$ & $4 / 21 / 09(2)$ & 3 & 2 & 0.071 & 0.091 \\
\hline $\mathrm{E}$ & $4 / 23 / 09$ & 1 & 2 & -0.108 & 0.008 \\
\hline $\mathrm{F}$ & $5 / 5 / 09(1)$ & 2 & 1 & -0.174 & 0.000 \\
\hline $\mathbf{G}$ & $\mathbf{5 / 1 9 / 0 9}(\mathbf{1}) *$ & $\mathbf{3}$ & $\mathbf{3}$ & $\mathbf{0 . 8 8 1}$ & $\mathbf{0 . 0 0 0}$ \\
\hline H & $\mathbf{5 / 1 9 / 0 9}(\mathbf{2}) *$ & $\mathbf{4}$ & $\mathbf{3}$ & $\mathbf{0 . 8 6 9}$ & $\mathbf{0 . 0 0 0}$ \\
\hline I & $\mathbf{6 / 2 / 0 9 *}$ & $\mathbf{4}$ & $\mathbf{1}$ & $\mathbf{0 . 8 3 0}$ & $\mathbf{0 . 0 0 0}$ \\
\hline J & $6 / 9 / 09$ & 4 & 3 & 0.267 & 0.000 \\
\hline
\end{tabular}

*Bold type indicates statistically significant sessions

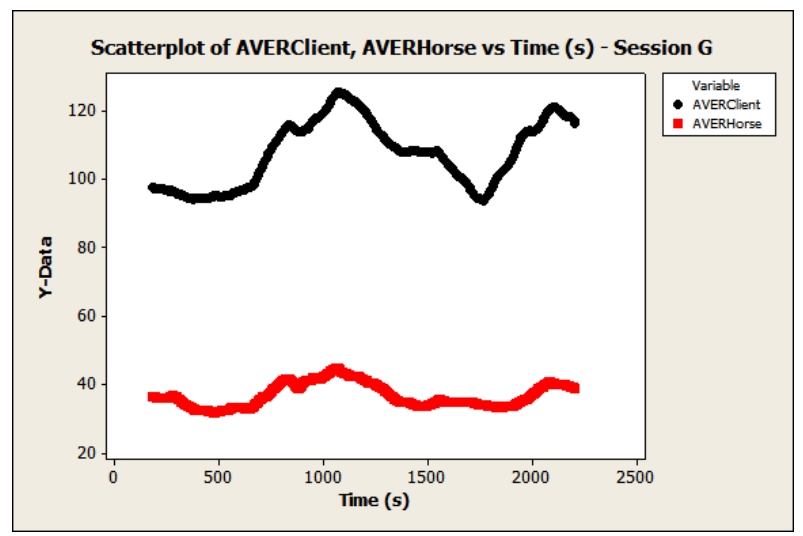

Figure 1: Horse and Client Heart Rate (bpm) vs Time (s) Session G

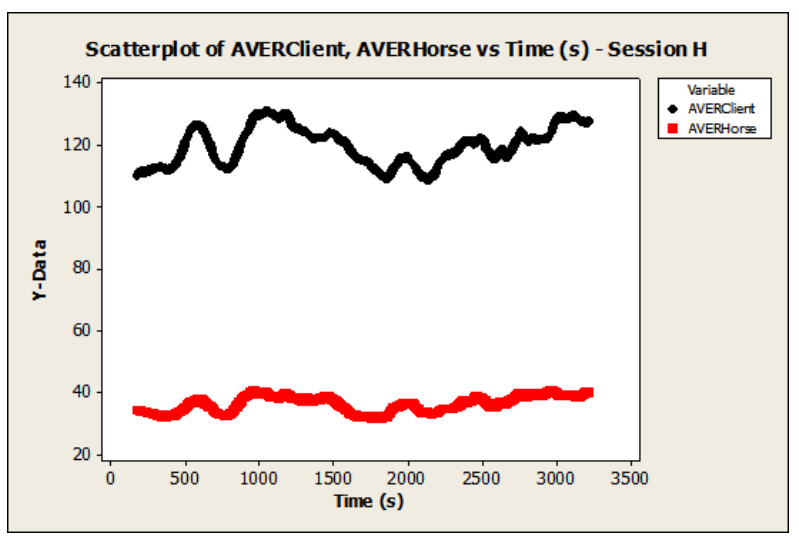

Figure 2: Horse and Client Heart Rate (bpm) vs Time (s) Session $\mathrm{H}$

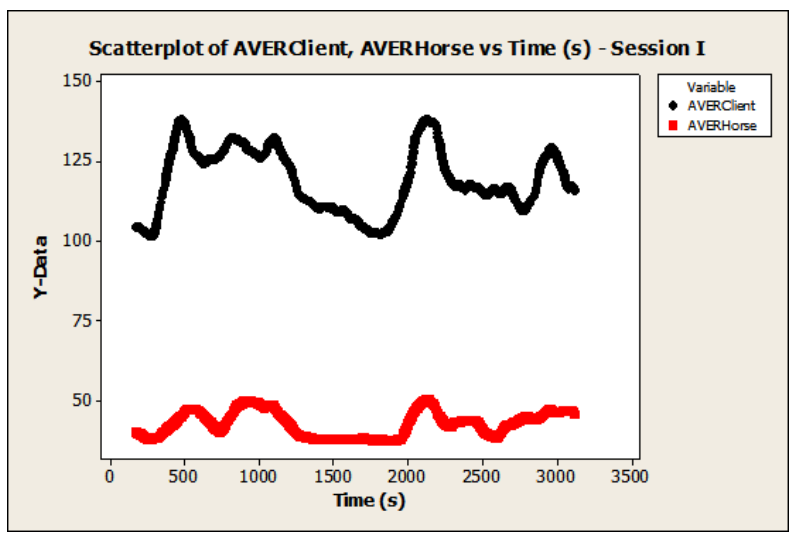

Figure 3: Horse and Client Heart Rate (bpm) vs Time (s) Session I

The only statistically significant time segment within Session $\mathrm{G}$ was from 940 - 1500 seconds. Horse and client heart rate decreased during this time. This segment included the bold font video occurrences during times 940 seconds to 1500 seconds (Table 2). 
Table 2: Description of Video Occurrences for Session G

\begin{tabular}{|c|c|}
\hline $\begin{array}{l}\text { Time Segment } \\
\text { (seconds) }\end{array}$ & Event \\
\hline 135 & Client meets hose \\
\hline 446 & $\begin{array}{l}\text { Client lifts, moves and slams down } \\
\text { poles }\end{array}$ \\
\hline 485 & $\begin{array}{l}\text { Client runs from one set of poles to } \\
\text { other }\end{array}$ \\
\hline $490-531$ & Continues to drag poles \\
\hline $557-589$ & Continues to drag poles \\
\hline 740 & Horse whinnies \\
\hline 785 & Client runs to corner \\
\hline 877 & Client runs to corner \\
\hline 918 & $\begin{array}{l}\text { Client attempts to hook up lead rope and } \\
\text { briskly walks after horse }\end{array}$ \\
\hline 1098 & $\begin{array}{l}\text { Client backs away from the horse } \\
\text { fearfully }\end{array}$ \\
\hline 1100 & Client hooks lead rope \\
\hline 1180 & $\begin{array}{l}\text { Client throws up hands and spooks } \\
\text { horse }\end{array}$ \\
\hline 1258 & Client repeats hand throwing action \\
\hline 1340 & Client repeats hand throwing action \\
\hline 1370 & Facilitator yells loudly \\
\hline 1425 & $\begin{array}{l}\text { Facilitator yells, stomps feet, and } \\
\text { spooks horse }\end{array}$ \\
\hline 1700 & $\begin{array}{l}\text { Client throws up hands and spooks } \\
\text { horse }\end{array}$ \\
\hline 1980 & $\begin{array}{l}\text { Horse steps on lead rope and startles } \\
\text { self }\end{array}$ \\
\hline 2116 & Client throws up hands again \\
\hline 2260 & $\begin{array}{l}\text { Loud noise outside, horse seems to take } \\
\text { notice }\end{array}$ \\
\hline 2520 & Horse nudges girls against wall \\
\hline
\end{tabular}

Session $\mathrm{H}$ did not contain any statistically significant time segments.

The time segment from 1005 - 1250 seconds was the statistically significant time segment within Session I. The horse and client hear rates decreased. However, there were no significant external events during times 1005 seconds to 1250 seconds.

\section{Discussion}

Briefly, the EAGALA model of therapy consists of four key components. The first is the team approach, with the team consisting of a licensed mental health professional, an equine specialist and a horse or horses working with clients in sessions. The role of the mental health professional is to guide the process of the session by use of Socratic questioning, by use of metaphorical dialogue and clientcentered approach. The equine specialist is someone trained to monitor the physical safety of the client and the physical and emotional safety of the horse while continuously monitoring the horse's behaviors for any signs of stress. The equine specialist also assists the mental health professional in recognizing shifts, patterns, unique responses and discrepancies in the horse's behavior and interactions with the client. For example, if a client were to report that a horse was upset when the horse was standing near the client with his head low, eyes half closed, ears to the side and hind foot resting, the equine specialist would be able to recognize the horse's behavior as that of a relaxed horse. The horse's role is merely to be itself. As horses are sentient beings and prey animals, they have an uncanny sense of reacting to their environment honestly and quickly. They have the ability to sense incongruence in people because this would be read as a potential danger from predators. In domestic horses, this ability enables horses to react to human emotions and behaviors on a moment-to-moment basis.

The second key component of the EAGALA model is a focus on the ground. This means that all sessions facilitated without the client ever mounting (riding) the horse. This allows the horse to behave as itself rather than responding to a person's commands or physical cues.

The key component is the solution-oriented processing. This is based on the observations that the clients have the best solutions for themselves. The facilitation team (primarily the mental health professional), helps the client to explore to find his or her own solutions. The client can then problem-solve, take risks, employ creativity and find what works best for him or her. For example, a client may be asked to encourage the horse to move into a designated part of the arena. The client may choose to guide the horse with tools that are in the arena, or to stand in the designated area and call the horse by name or any number of other things. In this study, the clients were given several different tasks throughout their sessions. The client was often asked if the horse or situation reminded them of anything in his or her life. The facilitators would then help to draw a parallel to how the horse was reacting to the situation the client presented. For example, if the client stated that the horse reminded the client of herself because he kept standing in the corner of the arena, the facilitators would assist in the examination of the mental processes that led the client to that conclusion (Equine Assisted Growth and Learning Association, 2006).

Lastly, the EAGALA model follows the EAGALA code of ethics and has a standard of professionalism which it employs. Analysis of a session as a whole revealed that 3 out of 10 sessions were statistically significant. When these sessions were then further analyzed, two time segments, each from different sessions, were statistically significant. Since the time segments were determined based upon graphical trends, we were able to determine if there was a potential external event contributing to the parallel trend in heart rate change for client and horse.

During the session $\mathrm{G}$, the time segment $940-1500 \mathrm{~s}$, both client and horse heart rates steadily decreased. The client and horse were in closer proximity than before. Both client and horse decreased physical activity at this point, which may account for a decrease in the heart rates. Due to the amount of possible variation from external events (i.e. the client throwing her hands up and spooking the horse) a significant correlation could be ruled in or out for this time segment. Session G video occurrences (Table 2) included several accounts of physical activity, such as: the client dragging poles, running, and the horse spooking, which could contribute to the correlation in horse and human heart rates during this session.

Session $\mathrm{H}$ was statistically significant as a whole, but no specific time segments within the session were statistically 
significant when analyzed further. We do not feel that this discounted the significance of session $\mathrm{H}$, as heart rate correlation was seen in Figure 2 and proven by the initial statistical analysis (Table 1). However, the external variables, such as the horse interacting with the cat, and physical activity of the client within session $\mathrm{H}$ (data not shown), could easily be the cause of the parallel trend in heart rate change for client and horse.

In Session I, time segment 1005 - 1250 seconds, both client and horse heart rate also steadily decreased. No significant external events were recorded during this time segment from the video data. It is therefore difficult to determine the origin of the correlation between client and horse heart rates during this time segment. It is possible that the lack of proximity between horse and client caused the decrease in stress levels and thus the decrease in heart rate.

\section{Conclusion}

Due to the amount of variation in physical activity and client / horse proximity in the therapy sessions the authors feel that the data is not empirically supportive of a basic physiological connection between horse and client. Upon comparison of video occurrences during the significant sessions and the heart rate scatter plots, external stimuli or physical activity coincide with human and horse heart rate variations. In order to achieve heart rate data indicative of stress, physical activity of both the client and the horse must be kept to a minimum and distance variation between the horse and client must be eliminated. Therefore, this pilot study could be beneficial in the design of a future study. A future study would maintain a setting such as a smaller arena space. Facilitation may be altered by increasing the distance between the facilitators and the client/horse. Standardization could be possible by utilizing the same activity across the subjects and the same horse across activities. External events in this setting would be more highly controlled and therefore one could more thoroughly examine solely the relationship between client and horse. Other measures of stress could also be examined such as behavior interpretation and serum cortisol levels. The authors hope that this study will lead to further studies that help to explain the positive benefits seen by equine assisted therapy.

\section{References}

de Jong, I.C., Sgoigo, A., Lambooij, E., Korte S.M., Blokhuis H.J., and Koolhaas, J.M. (2000). Effects of social stress on heart rate and heart rate variability in growing pigs. Canadian Journal of Animal Science 80, 273-280.

Equine Assisted Growth and Learning Association (2006). Fundamentals of EAGALA Model Practice, Equine Assisted Psychotherapy Certification Program, 13-18, 23-27.

Klontz, B.T., Bivens, A., Leinart, D., and Klontz, T. (2007). The effectiveness of equine-assisted experiential therapy: results of an open clinical trial. Society of Animals 15, 257-267. doi:10.1163/156853007X217195

Levinson, B. (1969) Pet-oriented child psychology. Springfield, IL: Charles C. Thomas.

Lynch, J.J., Fregin, G.F., Mackie, J.B., and Monroe, R.R. (1974). Heart rate changes in the horse to human contact. Psychophysiology 11(4), 472-478. doi:10.1111/j.14698986.1974.tb00575.x

Lynch, J.J. and Gantt, W.H. (1968). The heart rate component of the social reflex in dogs: The conditional effects of petting and person. Conditional Reflex 3, 69-80.

Marr, C.A., French, L., Thompson, D., Drum, L., Greening, G., Mormon, J., Henderson, I., and Hughes, C.W. (2000). Animal-assisted therapy in psychiatric rehabilitation. Anthrozoös 12(1), 43-47. doi: $10.2752 / 089279300786999950$

Mason, M.S. and Hagan, C.B. (1999). Pet-assisted psychotherapy. Psychological Reports 84, 1235-1245. doi:10.2466/PR0.84.3.1235-1245

Palestrini, C., Previde, E.P., Spiezio, C., and Verga, M. (2005). Heart rate and behavioural responses of dogs in the Ainsworth's Strange Situation: a pilot study. Applied Animal Behaviour Science 94, 75-88. doi:10.1016/j.applanim.2005.02.005

Rietmann, T.R., Stuart, A.E.A., Bernasconi, P., Stauffacher, M., Auer, J.A., and Weishaupt, M.A. (2004). Assessment of mental stress in warmblood horses: heart rate variability in comparison to heart rate and selected behavioural parameters. Applied Animal Behaviour Science 88, 121-136. doi:10.1016/j.applanim.2004.02.016

Visser, E.K., van Reenen, C.G., van der Werf, J.T.N., Schilder, M.B.H., Knaap, J.H., Barneveld, A. and Blokhuis, H.J. (2002). Heart rate and heart rate variability during a novel object test and a handling test in young horses. Physiology \& Behavior 76, 289-296. doi:10.1111/j.1471-0528.1982.tb04634.x

von Borell, E., Langbein, J., Despres, G., Hansen, S., Leterrier, C., Marchant-Forde, J.,... Veissier, I. (2007). Heart rate variability as a measure of autonomic regulation of cardiac activity for assessing stress and welfare in farm animals - A review. Physiology \& Behavior, 92, 293-316. doi:10.1016/j.physbeh.2007.01.007 